\title{
Management of Rangeland and Grazing-Determination of Stocking Rates
}

\author{
Michael A. Smith
}

$\mathrm{T}$ The determination of appropriate stocking rates for an area (animal unit months, AUMs, or animal numbers in units standardized by animal size times the length of grazing period; aka carrying capacity) for grazing animals is one of the most important tasks of rangeland managers (Holochek et. al. 1999). Customarily, stocking rates have been assumed to be static for a particular land area, and in historical practice, permits to graze public lands were fixed at a presumed economically or ecologically sustainable level. Forage use and animal performance would have varied yearly in response to growing conditions.

In recent years, on private pastures and public grazing lands, concerns for more efficient grazing use, improved animal performance, or improving resource conditions have suggested the need for more scientifically based determinations of stocking level. Arguably, the most effective and defendable method of assessing the appropriateness of currently used stocking rates is to monitor condition and trends of pertinent resource attributes and adjust grazing practices including stocking rate accordingly. Condition and trends would be determined by reliable sampling techniques, an application of "good" science. In addition, the grazing animal manager must assume much more responsibility for monitoring and timely adjustment of grazing in response to monitoring results. I will attempt to describe the essential elements of using annual animal use indicators and trend in condition of the resource to manage stocking levels.

\section{Concerns with Current Methods}

Many land managers and critics of grazing have tended to ignore the opportunity to learn from the relatively long history of grazing impacts implicit on most rangeland areas. These people are adhering to outmoded paradigms for determining appropriate stocking levels. The traditional methods applied to currently grazed areas result in unnecessary or misleading assessments of grazing levels.

Common problems with application of the traditional methods include inadequate sampling estimates of condition, utilization, annual fluctuations in weather effects, productivity, or animal distribution. Frequently no adjustment for seasons of grazing and training or herding of animals or other animal management practices of the permittee are made. Recent historic grazing levels and animal performance indicate at minimum that adequate forage is available to sustain the animals and resource condition problems if present are usually localized.

Traditional methods include the Natural Resources Conservation Services (NRCS) stocking rate guides. These guides require quantitative, rarely done, sampling of individual plant species productivity to determine condition class and assume continuous seasonal grazing with low intensity management practices. In their defense, NRCS guidelines are labeled suggested starting stocking rates and imply later adjustments. The U.S. Forest Service (USFS) manuals include production-utilization surveys that promote one-time stocking level adjustments based on usually limited data on annually variable utilization and production. These surveys adjust stocking level based on proportional differences in utilization from a predetermined allowable use level on key areas of the allotment. The assumption of proportionality between utilization on small key areas and stocking levels usually lacks any verified relationship for the specific land area.

Formulas that appear sophisticated have been proposed that assert that the appropriate stocking level should be based on livestock grazing characteristics described in the published literature (the text book approach, Holochek et al. 1989). The formula uses the distribution of grazing animals from other areas applied to the distances from water, slopes, species composition, and productivity of the subject area to hypothesize a stocking rate that is represented as carrying capacity. This approach ignores many factors important to effective range use including habitat's arrangement in the landscape, seasonal and annual differences in forage availability and palatability, weather, animal training, and herding practices.

A recent USFS Environmental Impact Statement (EIS) on management of Great Plains grasslands proposes to allocate forage for livestock grazing in a process based on 4 characteristics known or estimated; management area acres $X$ vegetation structural class percent $\mathrm{X}$ herbage production of site $\mathrm{X}$ allocated use level by structural class summed over all structural classes. This formula makes several arbitrary assumptions including plant growth allocations to plant health, wildlife, and livestock, presumed productivity, and, assignment of vegetation to structural (height) class es that appear to be derived from assessments with limited applicability or lack scientific literature verification. Grazing management practices, annual variability, and seasonal use patterns appear to be ignored.

These formula approaches may be an appropriate starting point on an area without a grazing history but they ignore many factors intrinsic to the area or controlled by the manager. In many examples, advocates of grazing practice reform point to these pseudo estimates of carrying capacity or reduced rangeland condition following past grazing practices to advocate reducing or eliminating grazing. An overwhelming deficiency in formula and one-size-fits-all stocking rate determinations is the implicit assumption that the number of animals using the area is the principle problem limiting resource condition. Critics often ignore or discount the numerous documented illustrations of improved conditions following the implementation of grazing practices that effectively control livestock distribution and use patterns. 


\section{An Alternative Stocking Rate Paradigm}

In any situation where stocking levels are being assessed, management goals for production or condition for the area being managed must be clearly stated and translated into measurable objectives. Evaluation of stocking rate may be required when some objective of management is not being met. Animal performance such as weight gains may be below expectations. Erosion of riparian and stream habitats, loss of upland vegetation composition, or watershed values may require improvements. Enough forage for other herbivores may not currently be left after livestock grazing. Effectively correcting deficient management actions or stocking levels imply that some level of trend monitoring and inventory of the area should be available to verify the specific kind, location, and extent of the deficiency. Cost, labor, or technical tools frequently limit the availability of appropriate inventory and monitoring information.

\section{Assessment}

A common example problem for public land grazing permittees and managers is that allotment riparian zones need more or taller willows to satisfy structural habitat diversity. Stream bank erosion or unsatisfactory spawning gravels reduce fish habitat value. A common response of managers to these ailments has been to recommend reductions in stocking level without consideration of the stocking history or grazing management. The recommendations commonly require arbitrary standards of percent of stream bank disturbance without site specific evaluation of the stream bank disturbance imposed by the geomorphology of the subject stream. For livestock grazing, this response by managers ignores several well known characteristics of livestock behavior and of alternative grazing management systems that may have great potential to solve the problem. The option of reducing numbers seems to surface just because it is simple to implement and managers know it was done on other areas. Frequently, reduced stocking rate is recommended without the prerequisite identification of the specific nature and extent of the problem.

\section{Inventory-Plan-Monitor-Replan}

In circumstances where a history of stocking levels exists and an inventory or even cursory assessment such as a Standards and Guidelines check has indicated that existing resource conditions are not satisfactorily meeting management goals, a logical course of action from managers should be as follows: 1) to identify what aspects of the grazing program may have resulted in the unsatisfactory resource condition, 2) establish measurable objectives for the resource components that identify the desired change in resource condition, 3) examine the feasibility of one or a combinations of management options such as planned grazing systems, vegetation stubble heights or utilization levels appropriate to suggest pasture moves, herding, season of use changes, or animal species changes, 4) implement the preferred grazing management strategy, 5)establish monitoring of annual use and weather and long term monitoring of change in measurable resource components, and 6) make timely annual adjustments and/or longer interval changes in the grazing strategy based on the monitoring results.

Successful implementation of the above process requires the incorporation of procedures or processes that arguably might be categorized as sociological as well as biological science based adaptive management. All stakeholders need an opportunity to participate and express their viewpoints in arriving at the management decisions. Stakeholders and especially the animal owner or manager should understand the goals, resource management objectives, and responsibilities for implementation of management on the unit.

Ecological potential, management cost, and management skills may limit what can be accomplished. The management strategy must be implemented as planned. If full implementation is limited by the time line for implementation of facilitation practices such as fences, water, or training of animals to herding, interim resource trend objectives and use targets should be established and as much of the management program as possible implemented to insure public awareness of attention to the apparent problem. Goals and objectives must be realistically attainable within the capability of the resource and managers.

\section{Science in This Process}

The integration of management and monitoring into an adaptive management strategy where monitoring feeds back directly to timely management adjustment is where good science can and should be applied. My use of "science" in this context primarily refers to the use of data developed through sampling processes that insure reliable data. Reliable data, whether of productivity, composition or utilization should be collected without bias and with sample sizes that provide acceptably small variation.

Ecological potential must be verified as this establishes the array of choices available for management goals. Monitoring must provide a reliable data foundation for management adjustments. Reliability explicitly involves data being representative of values for the component of the system being measured. The variation in the values must be low enough to realistically indicate the central tendency of the data, and the sampling technique must be usable by novices and subject to little variation in measurements by repeated observers on the same point.

Statistical reliability is insured by random or unbiased systematic selection of sample points from within the population (area, type, or species) being sampled. Other schemes for locating sample points will bias the sample results in whatever direction the scheme dictates, but for a specific purpose and with knowledge of the bias, alternative schemes may serve adequately if only a subset of the population, indicated by the bias, is of interest. Natural temporal and spatial variation in measured material cannot be avoided but the sample size, frequency of sampling, and technique should insure that this natural variation is accurately represented. Larger sample sizes or more frequent measurement may be necessary to accurately describe variation. Appropriate sample sizes can be calculated based on variation in a preliminary sample. Annual variation in growing conditions suggests that many measurements must be repeated until the expected range of resource values has been established. The sample technique should introduce minimal variation by being a relatively uncomplicated measurement and not subject to different interpretation of the material measured with different values 
obtained by a subsequent observer on a particular data point. A trend associated with management is indicated when the resource value changes over time are correlated with animal use and management and exceed the variation implicit in weather fluctuations over the period of record.

The animal manager would have primary responsibility for impacts of animals on the objective resource values. This manager must be able to make many of the measurements called for in the monitoring program in order to make timely management changes. The monitoring program must be based on enough simplicity in cost, sample size, location, and technique for the animal manager to quickly and reliably determine pertinent use impacts and trends in the resource being impacted. An ideal outcome of the implementation of grazing management predicated on annual and long term monitoring of use and resource conditions is that desired trends in resource conditions are accomplished and supported by reliable data open to scrutiny by resource managers or other stakeholders.

\section{An Example}

In one example of the implementation of the above process, a USFS allotment had concerns by Forest Service managers and other stakeholders of localized instances of excessive use exceeding forest plan standards on uplands, riparian zones, willows, and aspen. A coordinated resource management group was formed to address these problems. Key area, site specific objectives were established along with a grazing management plan to address these concerns in an allotment management plan. Monitoring was conducted for 4 years on various key areas included upland forage utilization percent, riparian species residual stubble height, percent grazed twigs on willows, and percent of grazed terminal buds on aspen, and willow and aspen height gain. In this period, use of willow by elk and cattle was also determined seasonally. Relatively high aspen use levels resulted in a program of sequentially fencing stands during cattle grazing periods to allow regeneration to get taller than browsing height. Elk were shown to consume more willow than cattle. Cattle were moved to the next pasture in the rotation as stubble height or utilization level targets were reached. After the 4 years of monitoring, the permittee was authorized to use a variable season-variable number permit with continuation of the rotational grazing, herding, monitoring, and aspen fencing because of the success of these practices in meeting the utilization standards for cattle. The length of the grazing season was variable depending on the length of time to reach the annual use targets. Key to success for the permittee was accepting the responsibility for continual monitoring of use that allowed for timely livestock herding and movement between pastures.

\section{Literature Cited}

Holochek, J. L., M. Thomas, F. Molinar, and G. Galt. 1999. Stocking desert rangelands: what we've learned. Rangelands 21:8-12.

Holochek, J. L., R. D. Pieper, and C. H. Herbel. 1989. Range management principles and practices. Prentice Hall, Englewood Cliffs, N.J. 501p.

Michael A. Smith, Professor, Renewable Resources Department, POB 3354 University Station, University of Wyoming, Laramie, WY 82071, 307-766-2337 (fax-6403), pearl@uwyo.edu.

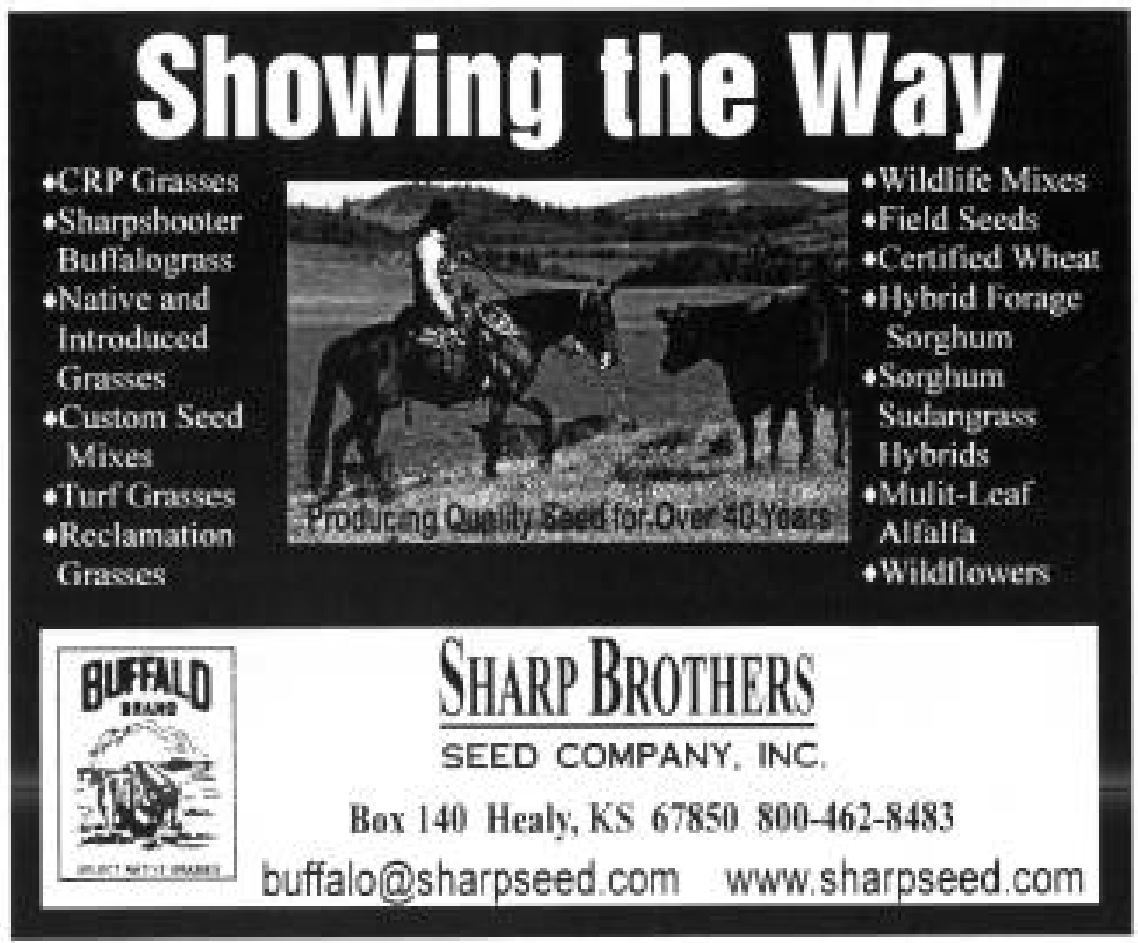

